\title{
Machado de Assis entre o jornal e o livro
}

Sílvia Maria Azevedo I Unesp/Assis

Resumo: Tendo em vista o projeto de formação do leitor nos contos publicados entre 1860-1877, serão apontadas as tensões entre um programa crítico que pressupõe a formação de um leitor ideal para a literatura e o fato de, nessa mesma época, o jovem Machado colocar em xeque tal programa ao escrever contos moralizantes e de matriz folhetinesca, enquanto colaborador do Jornal das Famílias (1863-1878). É só quando Machado seleciona os contos que irão integrar as duas coletâneas iniciais - Contos fluminenses (1870) $e$ Histórias da meia-noite (1973) - que épossivel perceber a operação analíticovalorativa de $\mathrm{O}$ ideal do crítico (1865) em atuação, tendo em vista o programa de formação do escritor e do público para a literatura. É nesse contexto que se dá a reescritura de contos do jornal para o livro, como é o caso de "O relógio de ouro" ou mesmo a inclusão de contos concebidos apenas para a edição em livro, a exemplo de "Miss Dollar", que abre estrategicamente a coletânea de Contos fluminenses com um endereço certeiro: o(a) leitor(a).

Palavras-chave: Machado de Assis, leitor, reescritura

Em 1859, o então jovem Machado de Assis - que há pouco ingressara no mundo do jornalismo e andava impregnado da leitura de E. Pelletan -, saudava, eufórico, o jornal como expressão de "perfectibilidade", "democracia" e "regeneração" 
O eixo e a roda: $v .16,2008$

da humanidade, "alavanca que Arquimedes pedia para abalar o mundo, e que o espírito humano, este Arquimedes de todos os séculos, encontrou." E, desafiador, indagava: "O jornal matará o livro? O livro absorverá o jornal?", questão que, examinada do ângulo social, literário e econômico, leva o crítico a decretar, embora com cautela: "[...] parece clara a possibilidade de aniquilamento do livro em face do jornal".

Em que pese o tom inflamado do jornalista que assina "O jornal e o livro", inebriado pelo próprio sucesso (e que já sabe aproveitar a ocasião para remeter a trabalhos anteriores que circulavam pela imprensa), há que se concordar que, no Brasil da época, era o jornal, e não o livro, que abria as portas para os jovens talentos, ávidos de ascensão social, como no caso do colaborador do Correio Mercantil. O livro, mercadoria cara e de circulação restrita, sempre esteve distante do universo de expectativas dos aspirantes a escritor. Enquanto o jornal, mais democrático, era o espaço de configuração da (ainda incipiente) república das letras brasileiras, tanto no que se refere ao universo do escritor quanto ao do leitor. Em ambos os casos, a atuação do crítico, cuja voz se fazia ouvir pelas páginas dos jornais, será decisiva. Mais uma vez é de Machado de Assis que virá o exemplo, tomado de "O ideal do crítico", publicado no ano seguinte, já agora no prestigioso Diário do Rio de Janeiro.

É ainda um crítico cheio de convicções e certezas, tal como o de "O jornal e o livro", que aqui se pronuncia: diante da "situação aflitiva" em que se encontrava a literatura brasileira (examinada em 1858, no ensaio "O passado, o presente, o futuro da literatura", que também saiu na Marmota), indica o estabelecimento da crítica "pensadora, sincera, perseverante, elevada" como "meio de reerguer os ânimos, promover os estímulos, guiar os estreantes, corrigir os talentos feitos". ${ }^{2}$ Embora, ao final - por conta talvez da leitura que Machado faz de Boileau -, irá recair sobre o crítico a mudança daquela "situação aflitiva", motivo por que "O ideal do crítico", como já foi sugerido, se permite ler como "O crítico ideal", ${ }^{3}$ para o qual são pontificadas "oito virtudes cardeais". ${ }^{4}$

Ainda assim, tratava-se de promover uma "reforma", tanto na literatura

1. MACHADO DE ASSIS, 1985, v. III, p. 944-946.

2. MACHADO DE ASSIS, 1985, v. III, p. 798.

3. MARTINS, 1952 , p. 145.

4. ATHAíde, 1985, v. III, p. 781. 
quanto no teatro então praticados no Brasil (lembrando agora de "Idéias sobre o teatro", publicado em $O$ Espelho, em 1858), tarefa que pressupunha o trabalho conjunto do crítico e do jornal: aquele no papel de "legislador", de "educador" do gosto do público, este no de promotor da discussão democrática. Dois outros canais, o Conservatório Dramático, "corpo policial" que, em assumindo, segundo Machado, os fins moral e intelectual para os quais fora criado, permitiria à instituição contribuir para a "educação" das platéias brasileiras, e a imprensa periódica recreativa, voltada para o âmbito doméstico e feminino, a exemplo do Jornal das Famílias (1863-1878), vieram colaborar, com igual empenho, na missão civilizadora de que se incumbiu a "nova geração" da qual Machado de Assis fazia questão de participar com indisfarçável orgulho.

Se a atividade crítica de Machado nos anos de 1860 se deixa ler, como já foi sustentado, como projeto de reforma do gosto literário dominante, reforma que passava pela educação estética do público leitor, e da qual o escritor vai se incumbir de levar a efeito quando se põe a escrever contos no Jornal das Famílias, ${ }^{6}$ é curioso pensar que esse projeto vinha pôr em xeque um tipo de literatura que encontrou larga acolhida no periódico de Garnier: o conto moral.

O conto moral, segundo Raimundo Magalhães Júnior, "surgiu como extensão das antigas fábulas, pequenas histórias acompanhadas de uma moralidade, destinada a explicar ao leitor menos agudo o seu sentido autêntico". ${ }^{7}$ É ainda em nome da eficácia da lição moral que o conto, ao lado da utilidade, deve igualmente oferecer divertimento, conforme se lê em "Um casamento de tirar o chapéu". Aqui se narram as desventuras de João Paulino, um pobretão que, em pensando dar o golpe do baú ao se casar com D. Isabelinha, acaba por herdar as dívidas do sogro. A certa altura, o narrador observa:

É preceito muito citado do velho Horácio, que nos escritos se deve misturar o útil com o agradável.

Foi esse preceito que tive em vista, escrevendo esta pequena história, onde, debaixo de uma forma agradável, se vê a infelicidade que pode resultar de fazer um casamento cujos contraentes são levados por um sentimento diverso da inclinação mútua que deve presidir a esse santo sacramento.

Outras características do conto moral que merecem destaque seriam:

5. MACHADO DE ASSIS, 1985, v. III, p. 790.

6. LOUREIRO, 2003.

7. MAGAlHÃes, 1972, p. 133.

8. Jornal das Famílias, tomo V, março de 1867 , p. 72. 
no plano da finalidade, a preocupação de oferecer ao leitor um retrato dos costumes da época; no plano da estrutura, a brevidade, o realismo (em atendimento da necessidade de oferecer uma lição verossímil ao leitor, para que este se reconheça nas personagens e na intriga), a unidade de universo.

Qual o leitor do Jornal das Famílias que não se identificaria com a personagem de Licurgo, de "Um provinciano ladino", que, vindo para a Corte, passa a ser explorado por um falso amigo, até que a adversidade o ensina a encontrar o seu caminho? Como não se comover com o zelo patriótico de D. Fernandina, de "Cecília a voluntária", de servir o Brasil na Guerra do Paraguai? Como não perceber, a partir do exemplo de Helena de Aguiar, de "A vaidade corrigida", que este é um vício que pode arruinar a vida de uma jovem?

A identificação do leitor com as personagens e a intriga resulta mais eficaz, se o narrador informar, como acontece na abertura de "Probidade de um sacristão", que a personagem da história não é um "ente imaginário", mas "um ente que realmente existiu, e a quem apenas mudei o nome para falar com maior liberdade". ${ }^{10}$ É possível pensar que, ao conferir o estatuto de ser real à protagonista do conto, o narrador assegura ao leitor que a narrativa pode ser lida com confiança, da mesma forma que merece crédito aquele que a está narrando.

Se é certo que o conto clássico (Poe, Quiroga, Tchecov, Maupassant) conta duas histórias, em princípio desvinculadas uma da outra, de modo a produzir, ao final, o efeito de surpresa, quando a história, que se mantinha secreta, vem à superfície, ${ }^{11}$ algo de inteiramente diverso acontece no conto moral. Embora aqui também seja empregada a técnica narrativa do encaixe, não é a surpresa o que liga uma história à outra, mas a redundância, a história de segundo plano comparecendo para reforçar, reiterar a de primeiro plano, tal como acontece em "A vaidade corrigida" e "Cecília a voluntária". No primeiro, é a vaidade das mulheres o vício a ser combatido, Eugênia deve e vai se corrigir por meio do exemplo de Helena de Aguiar. No segundo, a infração é ainda mais grave: D. Fernandina quer lutar na Guerra do Paraguai como soldado, mas é com a história trágica de Cecília Monteverde que irá se dar conta da impropriedade de uma mulher abandonar o lar e a família para servir a pátria (embora o Dr. Pecilgo, o relator da segunda história,

9. BeLlot-ANTONY, 1982, p. 83-88.

10. Jornal das Famílias, tomo VII, março de 1869, p. 83.

11. PIGLIA, 1991, p. 22. 
tenha de admitir que houve época, como durante a invasão holandesa, em que mulheres brasileiras combateram ao lado dos maridos).

Não é difícil imaginar a razão pela qual, a exemplo do que acontece nesses dois contos morais, personagens femininas atuando no papel de infratoras compareçam em quase todos os demais publicados no Jornal das Famílias. Basta lembrar que na carta-programa de janeiro de 1863, dirigida aos leitores, a redação do periódico não menciona a literatura entre as seções da sucessora da Revista Popular (1859-1862). Em compensação, não se esqueceu de "presentear" os assinantes (melhor dizendo, as assinantes) com "gravuras, desenhos a aquarelas coloridos, moldes de trabalhos de crochê, bordados, lã, tapeçaria, figurinos de modas", 12 o que parece indicar, em primeiro lugar, que, dentre os membros da família, a mulher é a figura a quem o Jornal das Famílias dedicará particular atenção. Em segundo lugar, que essa mulher deve ocupar-se com pequenos trabalhos de agulha, e não com a leitura (talvez, porque perigosa) de romances. Ilustrativa dessa concepção de mulher dona-de-casa é a estampa escolhida como capa do periódico: sentada numa cadeira de espaldar alto, uma jovem mulher, cuidadosamente vestida, aparece costurando.

Não por um acaso, vários contos publicados por Machado de Assis no Jornal das Famílias vão abordar a leitura feminina, em conformidade com a alusão às práticas de leitura, freqüente nos romances românticos brasileiros. ${ }^{13} \mathrm{~A}$ diferença, talvez, é que, em Machado, a alusão aparece em registro de ironia (o que já configura desvio em relação ao conto moral), tal como se dá em "O anjo das donzelas", "conto fantástico" publicado em 1864. Cecília, protagonista da história, é voraz leitora de romances. Por tomar tudo o que lê "ao pé da letra", na observação irônica do narrador, a mocinha passou a viver o medo de vir a sofrer do mal de amor. Até que um dia (melhor dizendo, uma noite), "o anjo das donzelas" vem salvar Cecília de semelhante percalço, propondo-lhe um pacto: a donzela ficará imune ao amor, e terá garantida a "eterna virgindade", ${ }^{15}$ desde que passe a usar um certo anel, para o resto da vida. Um dia o primo Tibúrcio, outrora um dos apaixonados de Cecília, acaba revelando que fora ele o autor do presente. Para

12. JORNAL DAS FAMÍLIAS, tomo I, jan. 1863, p. 1.

13. Lajolo; Zilberman, 1996, p. 252.

14. MAGALHÃes, s/d, p. 15.

15. MAGALHÃes, s/d, p. 15 . 
fazer chegar o anel até a prima, havia contado com a ajuda da mucama Teresa, que o introduzira no dedo da moça, no momento em que a outra dormia. Tudo, portanto, não passara de um sonho, melhor dizendo, de um equívoco de Cecília que, por tomar a ficção pela realidade, acaba sendo vítima da peça que lhe prega a literatura.

Em outra ocasião, e ainda a propósito da prática da leitura ao pé da letra, em perspectiva moralizante (conforme proposta do conto moral), Machado de Assis vai se fazer personagem na encenação de imoralidade, em que estava em causa outro conto de sua autoria. Trata-se de "Confissões de uma viúva moça", publicado no Jornal das Famílias, entre abril e junho de 1865. Por alguns dias, os "apedidos" do Correio Mercantil veicularam uma polêmica envolvendo O Caturra, leitor que acusava o conto de estar comprometendo o programa de um jornal "que se diz das famílias", e Machado, que, sob o pseudônimo J., saiu em defesa de sua obra. A alegação era de que, nem por haver leve referência, no primeiro capítulo do "romance", "Confissões de uma viúva moça", "às primeiras tentativas de um amante para alcançar o coração de uma mulher casada", "possa concluir-se pela imoralidade do resto". Protestando contra a "malignidade" e "caturrice" d'O Caturra, J. apela aos pais de família para que fiquem descansados, pois "o autor das Confissões respeita, mais que ninguém, a castidade dos costumes" - em que pese o convite ambíguo do narrador de "O anjo das donzelas: "Cuidado, leitor, vamos entrar no quarto de uma donzela". A (falsa) polêmica se encerra - parece que tudo não passou de golpe de publicidade tramado para atrair a atenção dos leitores, num momento em que o jornal tivera uma queda nas vendas, por conta do início da Guerra do Paraguai - quando Machado se revela o autor de "Confissões de uma viúva moça", e pede ao Sr. Caturra "que aguarde o resto do escrito para julgar de sua moralidade".

Se a polêmica nos "apedidos" do Correio Mercantilé falsa ou não, ela, de qualquer forma, mimetiza uma prática de leitura fundada na noção de identificação do leitor com a personagem e a intriga, fundamental como se disse, para a eficácia da literatura moralizante. Ora, e voltando ao chamado projeto de reforma do gosto do público leitor de literatura empreendido pelo crítico Machado de Assis, a viabilidade de tal projeto implicava que (alguns) dos contos que o escritor

16. MagalHÃes, s/d, p. 13.

17. MAGALHÃES, 1981, v. I, p. 322-326. 
publicou no Jornal das Famílias fossem levados para outro canal de circulação o livro -, sob o risco de serem lidos da forma como eram lidos (por efeito de contaminação) no periódico os contos morais.

Daí a organização das antologias Contos fluminenses, de 1870, e Histórias da meia-noite, de 1873. A respeito dos textos selecionados para integrar a primeira, pode-se dizer que a escolha de Machado não foi obra do acaso, como se quis ver, mas obedece a uma cronologia quase perfeitamente invertida. ${ }^{18} \mathrm{~A}$ coletânea se abre com "Miss Dollar" (o único conto que não foi publicado no Jornal das Familias e, para todos os efeitos, o último escrito) e se fecha com "Frei Simão" (o primeiro publicado no periódico, em junho de 1864), o que faz supor que Machado dispõe os textos na coletânea de 1870 nessa ordem, pretendendo que aqueles que vêm depois de "Miss Dollar" - no qual a leitura por identificação recebe tratamento metalingüístico - fossem lidos a partir dessa (outra) experiência de leitura literária.

Outro aspecto que permite identificar em Machado um projeto de reforma do gosto literário do leitor diz respeito às alterações introduzidas em alguns contos que foram trazidos para as duas coletâneas organizadas pelo escritor. Muitos exemplos poderiam ser mencionados, o que inclui a transformação de uma peça de teatro em conto, caso de Linha reta e linha curva, que antes de aparecer no Jornal das Famílias (publicado entre abril e junho de 1865) foi concebido como comédia, com o nome de Forcas caudinas, sendo escolhido para figurar em Contos fluminenses, ${ }^{19}$ até modificações de títulos, supressão de prefácios e finais moralizantes. Como aconteceu com "Ponto de vista", o último conto de Histórias da meia-noite e que apareceu no periódico em outubro e novembro de 1873. Dentre as alterações introduzidas por Machado de Assis figuram mudança de título - no Jornal das Famílias, o conto chamava-se "Quem desdenha..." -; supressão do prefácio e da última carta que compunha a narrativa.

No prefácio, lia-se o seguinte:

Não lhes posso dizer como vieram estas cartas parar às minhas mãos; afianço porém que são autênticas. Minha primeira idéia foi tirar do conteúdo delas o enredo de uma narrativa e fazer obra minha; assentei porém que era melhor transcrever as cartas sem lhes cortar uma vírgula

18. MASSA, 1971, p. 613.

19. SILVA, 2003. 
salvo o final da carta $\mathrm{V}$, por tratar exclusivamente de moda.

Dou a palavra às epístolas. ${ }^{20}$

Enquanto a carta XXIX, escrita por Raquel a Luísa, tinha o seguinte teor:

Corte, 14 de abril

O casamento é no dia 14 do mês que vem. Você devia ser convidada por força, isto porque (se não te opões) deves ser a minha madrinha.

Quer?

Quanto à razão do meu silêncio foram duas.

A primeira encontra-las-á nas cartas minhas que lá tens. Tanto mal disse de Alberto que me envergonhava de confessar o erro quando reconheci que as suas qualidades eram superiores.

Receei que se risse de mim.

Costumam dizer que as mulheres vêm a amar aquilo que mais desdenham. Eu tive medo de que me lançasse ao rosto esta versatilidade.

A segunda razão foi esta.

Não quis anunciar uma felicidade que poderia esvair-se. Ou por outra: não cantei vitória antes de ter o pássaro na mão.

E o pássaro está na mão.

Nunca vi amor mais submisso, mais completo, mais absoluto do que o dele. Se eu não for feliz, a culpa não será de Alberto.

Nem minha.

Adeus. $^{21}$

Se a intenção do narrador, no prefácio, era deixar claro que quem fazia as considerações introdutórias não era o mesmo que escrevera as cartas, com a supressão daquele artifício desaparece também o elemento que se interpunha entre as cartas e quem as vai ler. O que significa dizer que o narrador abriu mão de garantir a "autenticidade" do material que lhe foi "parar nas mãos". Ou ainda, quando o prefácio é posto de lado, desaparece o narrador preocupado em tranqüilizar o leitor - como acontecia nos contos morais - quanto à "veracidade" da história que vai ser contada.

Desaparecendo o narrador "interceptador" das cartas, o que acontecia

20. JORNAL DAS FAMÍlIAS, tomo XI, out. 1873, p. 306.

21. JORNAL DAS FAMÍlIAS, tomo XI, out. 1873, p. 310. 
em "Frei Simão", são elas que passam a falar por si mesmas ("dou a palavra às epístolas", diz o narrador) - lidas no calor da hora, pelo leitor e pela amiga -, o que faz com que o primeiro plano da narrativa seja ocupado (até certa altura) pela vOZ do "narrador protagonista" das cartas, isto é, a dissimulada Raquel que até o final escondera da amiga que ia se casar com o rapaz que sempre criticara. Por isso mesmo, são mais flagrantes as contradições, os ciúmes, os deslizes em Raquel do que em Eugênia, personagem de "Confissões de uma viúva moça", já que aqui predomina tão-somente a visão da "viúva moça", enquanto em "Ponto de vista" se dá um concerto de vozes, ou antes, de perspectivas.

O que o leitor presencia ao longo das 29 cartas que compõem o conto de 1873 é o espetáculo de uma capitulação: a segura Raquel, que nas primeiras cartas parecia estar absolutamente imune aos arroubos da paixão romântica, vai dando lugar à mocinha piegas que encontra no Dr. Alberto sempre menosprezado o homem ideal com quem vem a se casar. Dizer, no entanto, que "Ponto de vista" é a história da capitulação de uma moça que acaba por se revelar tão ou mais romântica do que as amigas criticadas, é reduzir o conto aos propósitos moralizantes de quando se chamava "Quem desdenha...". Como era moralizante o teor da carta XIX, ao ser publicada no Jornal das Famílias: o "mea culpa" de alguém que acaba por se render a quem sempre desdenhara, e que no livro dará lugar à perplexidade da amiga, não menor nem menos eloqüente do que sua resposta: "!!!"

Mais importante do que a capitulação de Raquel é a intenção de Machado de convidar o leitor à participação mais ativa na leitura das cartas, de forma a captar as nuances e os subentendidos que Luísa não soube perceber. Por isso é que, ao longo da narrativa, fica-se com a impressão de que, sob a aparência de uma inocente troca de cartas entre amigas, muitas coisas estão sendo omitidas. Daí que, nas cartas de Raquel, o leitor deve ler menos o que está escrito do que apreender o que não está dito.

Por isso também o conto "Ponto de vista" se presta ao desmascaramento da sinceridade das cartas: se delas já se disse que são "o espelho da alma", "o encontro das almas", não é o que acontece com as de Raquel, o tempo todo despistando, dissimulando, dizendo o não, mas querendo dizer o sim, dizendo o que não quer, para não dizer o que não pode (ou que tem vergonha de

22. MACHADO DE ASSIS, 1985, v. II, p. 250. 
admitir). Portanto, é por intermédio de Raquel, que sempre diz o contrário do que pretende, que a ironia se instala em "Ponto de vista". Se o leitor, aqui, é obrigado a proceder à leitura das entrelinhas, é porque deixou de ser tratado como "leitor ingênuo", "leitor curioso", leitor que "lê ao pé da letra", e entre ele e o narrador tem início uma relação, não mais de tutoria, e sim de cumplicidade. Que é quando começa igualmente a (verdadeira) literatura.

Resumen: Teniendo presente el proyecto de formación del lector en los cuentos publicados en el periodo entre 1860 y 1877, se indicarán las tensiones entre un programa crítico que presupone una formación ideal de un lector literario y el hecho que en esa misma época, el joven Machado coloque en evidencia tal programa al escribir cuentos moralizantes y de matriz folletinesca mientras se desempeñaba como colaborador en Jornal das Famílias (1863-1878). Solamente, cuando Machado seleciona los cuentos que integrarian las dos antologías -Contos fluminenses (1870) e Histórias da meia-noite (1973) - és posible percibir la operación analítica-valorativa del ideal do crítico (1865) en actuación, teniendo presente el programa de formación del escritor $y$ del público literato. Es en ese contexto que sucede la reescritura de los cuentos del jornal para el libro, como es el caso de "O relógio de ouro" u otros cuentos producidos especialmente para la edición del libro, ejemplo "Miss Dollar", que abre con táctica la antología de Contos fluminenses direcionados pertinentemente al lector.

Palabras-claves: Machado de Assis, lector, reescritura

$$
\text { Referências }
$$

ATAÍDE, Tristão de. Machado de Assis, o crítico. In: MACHADO DE ASSIS, Joaquim Maria. Obra completa. 5. ed. Rio de Janeiro: Nova Aguilar, 1985.

ANTONY, Michel Bellot. Les constantes d'un genre: le conte moral de Marmontel à Eric Rohmer. In: Frontières du récit. Paris: Editions du CNRS, 1982.

LAJOLO, Marisa; ZILBERMAN, Regina. A formação da leitura no Brasil. São Paulo: Ática, 1996.

LOUREIRO, Jaime Eduardo. O papel da crítica jornalística e da ficção na educação do leitor - Machado de Assis e a reforma do gosto literário. 2003. Dissertação (Mestrado) - PUC-SP, São Paulo, 2003. 
MACHADO DE ASSIS, Joaquim Maria. Contos avulsos. Organização e prefácio de Raimundo Magalhães Júnior. Rio de Janeiro: Tecnoprint, s/d.

Obra completa. 5. ed. Rio de Janeiro: Nova Aguilar, 1985, v. II e III.

MAGALHÃES JÚNIOR, Raimundo. A arte do conto: sua história, seus gêneros, sua técnica, seus mestres. Rio de Janeiro: Bloch, 1972.

Vida e obra de Machado de Assis. Rio de Janeiro: Civilização Brasileira; Brasília: INL, 1981.

MARTINS, Wilson. A crítica literária no Brasil. Rio de Janeiro: Francisco Alves, 1952.

MASSA, Jean-Michel. A juventude de Machado de Assis (1837-1870): ensaio de biografia intelectual. Trad. Marco Aurélio de Moura Matos. Rio de Janeiro: Civilização Brasileira; Conselho Nacional de Cultura, 1971.

PIGLIA, Ricardo. Tesis sobre el cuento. Revista Brasileira de Literatura Comparada. Niterói, v. 1, 1991.

SILVA, Ana Cláudia Suriani da. Linha reta e linha curva: edição crítica e genética de um conto de Machado de Assis. Campinas, SP: Ed. Unicamp, 2003. 